\title{
An Econometric Evaluation of the Performance of the Greek National Football Team
}

\author{
By Gregory T. Papanikos*
}

\begin{abstract}
This paper uses a Cobb-Douglas production function to account for the performance of the national football team. It is assumed that the capital and labor used in the production of football are constant proportions of the national capital and national labor. The performance of the Greek national team depends on the capitallabor ratio. Higher accumulation of capital, increases the performance of the national football team. Other variables are also found important such as the experience acquired by playing official games, the coach and the finals of the World and European Football Cup.
\end{abstract}

\section{Introduction}

National Football Team (NFT) performances have been examined by a number of empirical studies using panel data and a number of explanatory variables, including economic, demographic, and political characteristics. The dependent variable is the points each NFT wins. These points are officially reported by FIFA (Fédération Internationale de Football Association) but other measures have been used as well. This study contributes to this literature by (a) using a relatively long time series of data for only one country, i.e. Greece (b) building a different empirical model to determine the performance (production) of a NFT and (c) taking into consideration the two different measures of NFT performance. To my knowledge this is the first study that uses time series data of one country to test NFT performance.

NFT performance can be considered as a pure public good. It is produced by the use of capital, labor and other factors of production such as accumulated knowledge, exceptional skilled labor, and specific climatic conditions. The demand for NFT's output is non-excludable and non-rivalrous. It is like national defense. Nobody can be excluded from consuming it and one's consumption does not diminish the use of others. In this study, the production of Greek NFT's output can be approximated by a constant returns to scale Cobb-Douglas production function.

Hoffman et al (2002) is the first study to regress the FIFA measurements of national football performance on economic, population, cultural and climatic variables. They used a sample of 76 countries and FIFA rankings of January

${ }^{*}$ Honorary Professor of Economics, University of Stirling, UK and Vice President, Panhellenic Association of Sports Economists and Managers (PASEM) and President Athens Institute for Education and Research (ATINER). 
2001. They found that per capita income has a non-linear impact on national football teams' performances. An increase in per capita income increases the performance but at a decreasing rate. On the other hand, population was found to be not statistically significant. The squared of the average annual Celsius temperature in country A's capital minus 14 was used as an explanatory variable. This had an expected negative impact. Two dummy variables to account for world cup hosting countries and Latin countries were used. Both were found to have a positive impact. An interaction term between Latin origin and population size shows that the population of a Latin country has had a positive impact on performance.

MacMillan and Smith (2007) extended the above model by increasing the sample size to include 176 countries. This reduces the bias and inconsistency of the ordinary least square (OLS) estimators. In addition they used an additional measurement of performance suggested by professor Arpad Elo. This is commonly known as the "Elephant" measurement. The impact of output was similar as in the previous study but contrary to previous findings, this study found a statistically significant impact of both the level of population and the population squared. The history of the national team, i.e. the year it played its first international match, had also a statistical significant and positive impact.

This study is organized in seven sections, including this introduction. Section two develops a simple theoretical production function model to account for the Greek NFT performance. Section three presents data on the two measurements of the Greek NFT performance and section four discusses some of the historical successes of the Greek team. Section five reports the descriptive statistics of the data used in the regression analysis and test the time series properties of the data. Section six gives and discusses the empirical results. Section seven concludes.

\section{A Simple Production Function to Account for NFT's Performances}

The few studies which account for the determinants of football performance of a national team emphasize three types of variables. First, variables which describe team specific characteristics such as the quality of the players, including the role of star players, the ability of the coach, the organization and management of the team, etc. Second, variables that account for specific conditions of a match such as the weather conditions, the number of attendees, the home advantage, the experience of the team etc. Third, variables that are not directly related to football such as the economic, demographic and political conditions of national football teams' countries involved in the match.

In a time series analysis, this approach becomes problematic. As we shall see below, the measurement of performance is stationary in levels while output, population and per capita income are not stationary. Thus, the variables 
are not cointegrated, implying that a behavioral relationship does not exist and any regression will give spurious results.

This study follows a different approach. It assumes that the performance of a national football team is produced by the use of labor and capital that are proportional to aggregate (national) capital and labor. Furthermore, it is assumed that this relation is stable, which is a valid assumption in the football industry because the game is played (produced) almost the same way for decades. It is supposed that the output of a national football team can be approximated by a constant elasticity Cobb-Douglas production function of the following type:

$$
\mathrm{Q}_{\mathrm{NFT}}=\mathrm{F}\left(\mathrm{K}_{\mathrm{NFT}}, \mathrm{L}_{\mathrm{NFT}}\right)=\mathrm{A}\left(\mathrm{K}_{\mathrm{NFT}}\right)^{\alpha}\left(\mathrm{L}_{\mathrm{NFT}}\right)^{(1-\alpha)} \mathrm{e}^{\mathrm{d}} \mathrm{e}^{\mathrm{u}}
$$

where $\mathrm{Q}_{\mathrm{NFT}}$ is the output of the national football team produced by capital $\mathrm{K}_{\mathrm{NFT}}$ and labor $\mathrm{L}_{\mathrm{NFT}}, \mathrm{A}>0$ is an efficiency parameter, $\boldsymbol{\alpha}$ lies between zero and one, $\boldsymbol{d}$ represents a vector of dummy variables to be discussed later in the empirical part of the paper and $\boldsymbol{u}$ is an error term, normally and identically distributed with zero mean and constant variance. This production function is assumed to exhibit constant returns to scale.

As mentioned above, the capital stock and the labor used in the national football team's performance is assumed to be a stable fraction of the national capital stock and national employment level.

(2) $\quad \mathrm{K}_{\mathrm{NFT}}=\mathrm{k}_{\mathrm{p}} \mathrm{K}$ and

(3) $\quad \mathrm{L}_{\mathrm{NFT}}=1_{\mathrm{p}} \mathrm{L}$

where $k_{p}$ and $l_{p}$ are positive fractions of national (aggregate) capital $(\mathrm{K})$ and labor (L) used in football production. Substituting (2) and (3) into equation (1) gives:

$$
\mathrm{Q}_{\mathrm{NFT}}=\mathrm{A}\left(\mathrm{k}_{\mathrm{p}} \mathrm{K}\right)^{\alpha}\left(\mathrm{l}_{\mathrm{p}} \mathrm{L}\right)^{(1-\alpha)} \mathrm{e}^{\mathrm{u}}=\mathrm{Ak}_{\mathrm{p}}{ }^{\alpha} \mathrm{l}_{\mathrm{p}}^{(1-\alpha)}(\mathrm{K})^{\alpha}(\mathrm{L})^{(1-\alpha)} \mathrm{e}^{\mathrm{u}}=\mathrm{A}^{\prime}(\mathrm{K})^{\alpha}(\mathrm{L})^{1-\alpha} \mathrm{e}^{\mathrm{d}} \mathrm{e}^{\mathrm{u}}
$$

where $A^{\prime}=A_{p}{ }_{p}^{\alpha} 1_{p}^{1-\alpha}$. Constant returns to scale imply that the output per labor depends only on the capital-labor ratio and not on the scale of production. Thus, the above production function can be written as:

$$
\left(\mathrm{Q}_{\mathrm{NFT}}\right) / \mathrm{L}=\mathrm{A}^{\prime}(\mathrm{K} / \mathrm{L})^{\alpha} \mathrm{e}^{\mathrm{d}} \mathrm{e}^{\mathrm{u}}
$$

This equation is easily estimated in its logarithmic transformation:

$$
\mathrm{q}=\mathrm{c}+\alpha \mathrm{k}+\mathrm{d}+\mathrm{u}
$$

where $\left.\mathrm{q}=\log \left[\mathrm{Q}_{\mathrm{NFT}}\right) / \mathrm{L}\right], \mathrm{c}=\log \left(\mathrm{A}^{\prime}\right)$ and $\mathrm{k}=\log (\mathrm{K} / \mathrm{L})$ 
Equation (6) is estimated using Greek time series data. The parameter estimates are reported later in the paper. In the next section, the measurement of Greek NFT performance is discussed.

\section{The Measurements of Greek NFT Performance}

This study uses the annual points gained per match by the Greek national football team as a measure of performance (production). Two methods have been used to measure performance. One has been suggested by FIFA, which can be considered as an official measure of performance. The second is an adaptation of the Elo rating system named after its creator Arpad Elo, a physics professor. Originally, the Elo rating was used in chess but it has been adapted to many other sports, including football teams.

The difference is the treatment of the official and friendly games. FIFA takes into consideration the friendly games but Elo does not. However, both give zero points for a lost game. Both approaches are used here to construct indices of football performance. In this study, the importance of the opponent is not taken into consideration because data do not exist over this long period of time for all opponents. For example, the Soviet Union and Yugoslavia do not exist after 1989. The strength of the rival team is important to explain goal differences and thus points gained in a specific match. In this analysis, the average points gained per match each year is used and therefore in a given year a national football team plays games against weak and strong opponents. In other words, it is assumed that the average strength of the opponents played every year does not change.

Summary statistics of the two measurements are given in Table 1 and their cross correlations are given in Tables 2. Two sample periods are reported, 1960-2014 and 1974-2014. As discussed and tested later, there is a breakdown in the time series after 1974. The lowest points per year are obtained with the Elo measurement because it does not count friendly games. The annual average score of the Greek national football team over the 55 (41) years of the 19602014 (1974-2014) period was 261 (274) FIFA points and 197 (208) Elo points. The frequency distribution of the two measures and for the two periods is skewed to the right as shown by the median value relative to the mean and the value of skewness. The kurtosis values show and the Jarque-Bera tests reject the hypothesis of normal distribution for the 1960-2014 but fails to reject it for the 1974-2014 period. The $\mathrm{NFT}_{\text {Elo }}$ does not take into consideration results from friendly games showing a greater variation of points obtained every year than

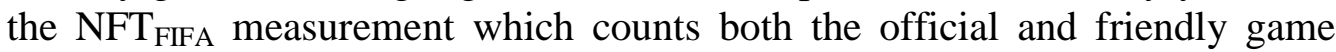
results. The maximum points obtained in the 1960-2014 period were 750 and 542 for the 1960-2014 period. Greater standard variations are obtained for the $\mathrm{NFT}_{\text {Elo }}$ measurement as well as for the 1960-2014 period. As shown in Table 2, the two measurements exhibit strong correlation of $93 \%$. 
Table 1. Summary Statistics of the Two Measures of the Greek NFT Performance

\begin{tabular}{|c|c|c|c|c|}
\hline & $\begin{array}{c}\mathrm{NFT}_{\text {FIFA }} \\
1960-2014\end{array}$ & $\begin{array}{c}\mathrm{NFT}_{\text {Elo }} \\
1960-2014\end{array}$ & $\begin{array}{c}\mathrm{NFT}_{\text {FIFA }} \\
1974-2014\end{array}$ & $\begin{array}{c}\mathrm{NFT}_{\text {Elo }} \\
1974-2014\end{array}$ \\
\hline Mean & 260.9636 & 196.5818 & 273.6098 & 207.7805 \\
\hline Median & 250.0000 & 188.0000 & 256.0000 & 194.0000 \\
\hline Maximum & 750 & 750 & 542 & 542 \\
\hline Minimum & 20 & 0.0 & 121 & 21 \\
\hline Std. Dev. & 136.1716 & 148.2645 & 108.6402 & 123.7258 \\
\hline Skewness & 0.966641 & 1.271510 & 0.673503 & 0.845762 \\
\hline Kurtosis & 4.727833 & 5.358714 & 2.986862 & 3.452188 \\
\hline Jarque-Bera & 15.40684 & 27.56985 & 3.099933 & 5.237284 \\
Probability & 0.000451 & 0.000001 & 0.212255 & 0.072902 \\
\hline Sum & 14353.00 & 10812.00 & 11218.00 & 8519.000 \\
\hline Observations & 55 & 55 & 41 & 41 \\
\hline
\end{tabular}

Table 2. Correlation Matrix, 1960-2014

\begin{tabular}{|c|c|c|c|c|}
\hline & NFT $_{\text {FIFA }}$ & NFT $_{\text {Elo }}$ & NFT $_{\text {FIFA }}$ & NFT $_{\text {Elo }}$ \\
& $1960-2014$ & $1960-2014$ & $1974-2014$ & $1974-2014$ \\
\hline NFT $_{\text {FIFA }}$ & 1.000000 & 0.930618 & 1.000000 & 0.938435 \\
\hline NFT $_{\text {Elo }}$ & 0.930618 & 1.000000 & 0.938435 & 1.000000 \\
\hline
\end{tabular}

The FIFA and the Elo measurements have been used in the empirical literature of the determinants of NFT. These studies use panel data. They are regressed on a number of explanatory variables which include GDP, population, political conditions and a number of other variables. If employment is proportional to population and GDP proportional to capital, then, in effect, these studies estimate a production function using GDP and population as proxies for capital and employment respectively. However, the stationarity properties of GDP, population and measurement of football performance are not the same and therefore cannot be used in a time series model. These studies which use panel data do not test for the stationarity purposes of the variables. The stationary properties of the data are reported later. The next section briefly presents the historical performance of the Greek national football team.

\section{The Successes of the Greek NFT}

The year 2004 will be remembered by many Greeks for years to come. It was in 2004 that Greece organized the Olympic Games with great success, won the Eurovision Competition and the least expected of all her National Football Team won the trophy of the European Football Championship. It was Greece's second appearance in such a European Cup competition.

Greece's history of football goes back to the 1920s but a number of political and military (war) occurrences prevented the development of the sport at a pace similar to other western European countries, such as in the neighboring country of Italy. Up to the late 1950s, the Greek National Team was so weak that whenever strong national football teams like those of France, 
Italy and Spain, played against Greece, they used second class players in their lineups. Thus, matches played up to 1960 are not directly related with those played after that period. Since then, Greek football has become stronger and stronger. By the end of the 2014 world cup, Greece ranked as one of the top 20 strongest national football teams in the world.

\section{The World Ranking of the Greek National Football Team}

Besides the great success of the 2004 win of the European championship, the Greek NFT has succeeded to qualify three times in its history to the World Finals (1994, 2010 and 2014) and four times to the European Finals (1980, 2004, 2008 and 2012). In 2005 it played in the confederation cup as a European Champion. In 1993, FIFA created a ranking system of NFTs based on a weighted average of game results, the strength of the opponent and the significance of the game. The ranking of the Greek NFT is shown in Table 3. The average ranking position of the Greek NFT of the 1993-2014 period was 26.

Since 2004, the Greek national team was ranked in top 20 teams world list. The total number of national teams exceeds 200 countries. Table 3 shows that the win of the European Champion was not a gleam. Since then, Greece has qualified to play in four finals, missing only the 2006 World Cup Finals. Greece played in the European Finals in 2008 and 2012, and the World Cup Finals in 2010 and 2014. In 1993 Greece ranked $34^{\text {th }}$ in the relative list. During 1993-2002 its relative position was declining, reaching as low as the $57^{\text {th }}$ place. The average position of this period is $40^{\text {th }}$. Starting in 2003, the Greek national team reached the top 20 list. The average position of the last 10 years is $14^{\text {th }}$ place.

Table 3. World Ranking of the Greek National Football Team based on FIFA's Count

\begin{tabular}{|c|c|c|c|}
\hline Year & $\begin{array}{c}\text { FIFA Word } \\
\text { Ranking }\end{array}$ & Year & $\begin{array}{c}\text { FIFA Word } \\
\text { Ranking }\end{array}$ \\
\hline 2014 & 12 & 2003 & 30 \\
\hline 2013 & 12 & 2002 & 48 \\
\hline 2012 & 11 & 2001 & 57 \\
\hline 2011 & 14 & 2000 & 42 \\
\hline 2010 & 11 & 1999 & 34 \\
\hline 2009 & 13 & 1998 & 53 \\
\hline 2008 & 20 & 1997 & 42 \\
\hline 2007 & 11 & 1996 & 35 \\
\hline 2006 & 16 & 1995 & 34 \\
\hline 2005 & 16 & 1994 & 28 \\
\hline 2004 & 18 & 1993 & 34 \\
\hline
\end{tabular}

Note: The year 2014 includes the average of the first 7 months.

\section{The Number of Games Played}

Greece's first game was a friendly match with an Italian team that took place on the $7^{\text {th }}$ of May 1929 in Athens. The last to be considered in this study 
is the match against Costa Rica, a knock out game in the round of 16 in the 2014 World Cup Finals. In total, the Greek NFT has played 549 games of which 301 were official and 248 were friendly games. After 1960, the Greek team played 479 games of which 244 were official games. Figure 1 shows the number of games, total and official, played every year since 1960. On average they played 8.7 total games per year of which 4.44 were official.

It is clear from the graph that the number of games increased after 1974 which is considered as a structural break to be tested later in the paper. Before 1974 the average number of total games played was 5 per year but it doubled to 10 games per year after 1974. Similar is the increase in the official games. From 2.8 games in the 1960-1973 period, it increased to 5 games per year in the 1974-2014 period. This is important because the number of official games can increase only if the national team qualifies for the next rounds which on average give more points, increasing the average number of points per game.

Very important for this study is the type of teams Greece has played against every year. The official games are always a mixture of strong, medium and weak teams because the preliminary rounds of the two most important tournaments, the European and the World cup are made up of a mixture of teams according to their strength. Thus, every team plays both weak and strong teams. This approach of making up the groups is followed in both the European and the World Finals. Thus, every year, the Greek team has played with both strong and weak football teams.

Figure 1. Total and Official Games Played by the Greek NFT, 1960-2014

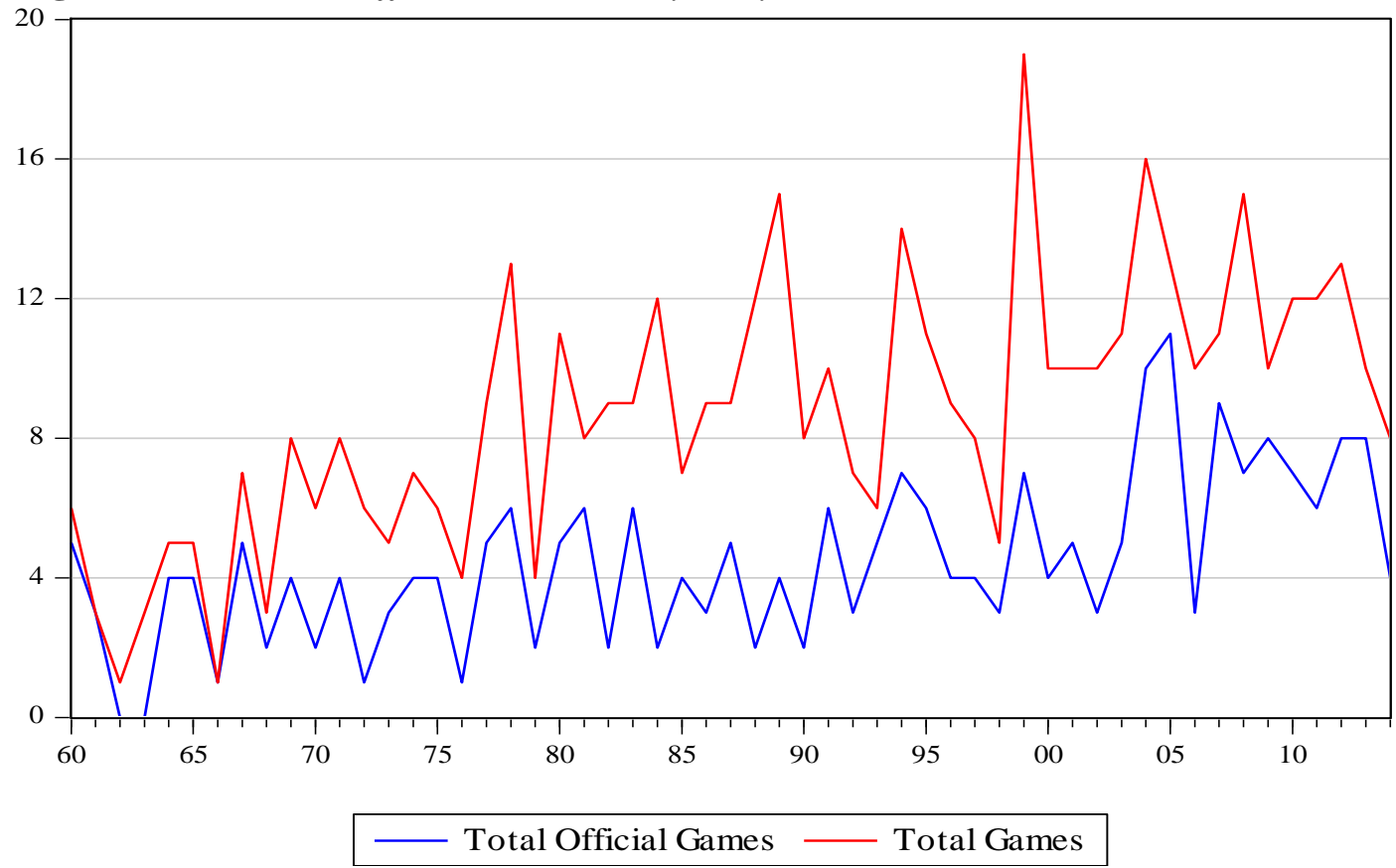


Table 4 gives the teams and the number of times they played against the Greek team in official games over the 1960-2014 period. Greece has played 244 games against 57 teams. The 57 teams account for about 25\% of the world's national football teams. Thus, Greece had never played against teams of the $75 \%$ of countries whose national teams are FIFA members. As can be seen from Table 4, there is a balance of weak and historically strong teams. Greece has played eight times against Germany and England, six times against Spain and two times against Italy. On the opposite weaker side Greece has played ten times against Malta, eight times against Luxembourg, and two times against Faeroe islands and Lichtenstein. However, some teams have not remained stable in terms of their classification of strong and weak teams. Hungary, for example, was a very strong team but lost its strength in the last decades.

Table 4. Rival Teams and Number of Times Played by Greece in Official Games

\begin{tabular}{|c|c|c|c|c|c|}
\hline Team & Number & Team & Number & Team & Number \\
\hline Hungary & 12 & Bosnia & 6 & Iceland & 2 \\
\hline Denmark & 12 & Poland & 5 & France & 2 \\
\hline Malta & 10 & Holland & 5 & $\begin{array}{l}\text { Faeroe } \\
\text { islands }\end{array}$ & 2 \\
\hline Finland & 10 & Turkey & 4 & Cyprus & 2 \\
\hline Romania & 9 & Slovenia & 4 & Belgium & 2 \\
\hline Soviet Union & 8 & Norway & 4 & Austria & 2 \\
\hline Luxembourg & 8 & Moldavia & 4 & Armenia & 2 \\
\hline Germany & 8 & Ireland-N & 4 & Argentina & 2 \\
\hline England & 8 & Croatia & 4 & Sweden & 1 \\
\hline Albania & 8 & Slovakia & 3 & Mexico & 1 \\
\hline Yugoslavia & 7 & Lietuva & 3 & Korea-S & 1 \\
\hline Russia & 7 & $\begin{array}{c}\text { Czech } \\
\text { Republic }\end{array}$ & 3 & Ivory Coast & 1 \\
\hline Latvia & 7 & Wales & 2 & Costa Rica & 1 \\
\hline Ukraine & 6 & Scotland & 2 & Colombia & 1 \\
\hline Switzerland & 6 & San Marino & 2 & Brazil & 1 \\
\hline Spain & 6 & Nigeria & 2 & Iceland & 2 \\
\hline Portugal & 6 & Lichtenstein & 2 & France & 2 \\
\hline Israel & 6 & Kazachstan & 2 & & \\
\hline Georgia & 6 & Japan & 2 & & \\
\hline Bulgaria & 6 & Italy & 2 & & \\
\hline
\end{tabular}

\section{Descriptive Statistics and the Time Series Properties of the Data}

This section presents and discusses the summary of the data used in the estimation of equation (6) above. The dependent variable is the logarithm of the ratio of Greek NFT performance measurement divided by total Greek employment. Table 5 reports summary descriptive statistics of the FIFA and the Elo NFT performance measurement for the 1960-2014 and 1974-2014 periods. The difference between the two periods is the normality assumption. 
The hypothesis of normal distribution is rejected for the 1960-2014 period but cannot be rejected for the 1974-2014 period as is shown by the values and probabilities of the Jarque-Bera test ${ }^{1}$. Thus, the regression estimation of the parameters of equation 6 above is applied to the 1974-2014 period.

Table 5. Data Summary

\begin{tabular}{|c|c|c|c|c|}
\hline & $\mathrm{q}_{\mathrm{FIFA}}$ & $\mathrm{q}_{\mathrm{ELO}}$ & $\mathrm{q}_{\mathrm{FIFA}}$ & $\mathrm{q}_{\text {ELO }}$ \\
& $1960-2014$ & $1960-2014$ & $1974-2014$ & $1974-2014$ \\
\hline Mean & 4.045849 & 3.553439 & 4.135071 & 3.727948 \\
\hline Median & 4.164486 & 3.913571 & 4.164486 & 3.928661 \\
\hline Maximum & 5.376207 & 5.376207 & 4.902990 & 4.902990 \\
\hline Minimum & 1.762007 & 1.015283 & 3.468981 & 1.673849 \\
\hline Std. Dev. & 0.589579 & 1.000189 & 0.364115 & 0.700831 \\
\hline Skewness & -1.179523 & -1.133268 & -0.116561 & -1.094799 \\
\hline Kurtosis & 6.135160 & 3.916151 & 2.579479 & 4.427511 \\
\hline Jarque-Bera & 35.27865 & 13.69618 & 0.394940 & 11.67155 \\
\hline Probability & 0.000000 & 0.001061 & 0.820805 & 0.002921 \\
\hline Sum & 222.5217 & 195.4392 & 169.5379 & 152.8459 \\
\hline Sum Sq. Dev. & 18.77056 & 54.02039 & 5.303189 & 19.64658 \\
\hline Observations & 55 & 55 & 41 & 41 \\
\hline
\end{tabular}

In order to obtain meaningful results, all variables must be stationary. Table 6 reports test results for unit roots using the Augmented Dickey-Fuller test. It is concluded that the variables of the model are stationary and the method of least squares can be applied to estimate the parameters of the model.

Table 6. Test for Unit Roots, 1974-2014

\begin{tabular}{|c|c|c|c|}
\hline & $\begin{array}{c}\text { ADF with Intercept } \\
\text { (probability) }\end{array}$ & $\begin{array}{c}\text { ADF with Intercept } \\
\text { and a Trend } \\
\text { (probability) }\end{array}$ & $\begin{array}{c}\text { ADF with } \\
\text { None } \\
\text { (probability) }\end{array}$ \\
\hline \multirow{2}{*}{ q FIFA $^{*}$ q $_{\text {Elo }}$} & $\mathbf{- 7 . 9 3}$ & $\mathbf{- 9 . 2 7}$ & 2.10 \\
\multirow{2}{*}{$\mathrm{(0.0001)}$} & $\mathbf{- 6 . 3 4}$ & $\mathbf{( 0 . 0 0 0 1 )}$ & $(0.99)$ \\
\hline & $\mathbf{( 0 . 0 0 0 1 )}$ & $\mathbf{- 6 . 8 6}$ & 1.13 \\
& -1.70 & $\mathbf{0 . 0 0 0 1})$ & $(0.9313)$ \\
\hline Log(official games) & $(0.4246)$ & $\mathbf{- 3 . 5 8}$ & 2.46 \\
& -1.82 & $\mathbf{0 . 0 4 4 3 )}$ & $(0.9960)$ \\
\hline
\end{tabular}

Note: Bold letters indicate that the hypothesis of the stationarity cannot be rejected. The data on capital and labor are retrieved from Eurostat's AMECO database.

\footnotetext{
${ }^{1}$ Additional tests for normal distribution, such as the Andesrson-Darling test, fail to reject the hypothesis of normality for the shorter sample period for the FIFA measurement but it is rejected for the Elo measurement.
} 


\section{Regression Results}

Stationarity of the variables implies that the linear regression model can provide efficient and unbiased estimates of the parameters of the model. Table 7 reports estimates of the parameters of the models, using the two different measures of football performance. The estimates of the simple model are reported in Columns (1) and (2) and those of the extended model in Columns (3) and (4) of Table 7. Estimates are reported only if they are statistical significant in at least one regression model. All estimated parameters of the variables have the expected sign. The null hypothesis of homoskedasticity cannot be rejected (statistics are not reported) with any of the conventional tests for heteroskedasticity.

The goodness of fit ranges from $6 \%$ to $46 \%$. The best fit is given by the FIFA measurement of $19.94 \%$ in the simplest model and $46 \%$ in the extended model. In addition to capital-labor ratio, the extended model includes the number of official games played per year and the dummy variables that account for (a) games played in world or European finals, and (b) the three important coaches which have as a common characteristic the qualification to a European or world finals. Only the dummy variable of coach Panagoulias was statistical significant.

The capital-labor ration has a positive impact. In the simplest model the share of capital (the value of the parameter of equation 6 above) is 0.82 . According to the theoretical restrictions of constant returns to scale, the parameter estimate should be less than one. A Wald test does not reject the hypothesis of less than one in all four model specifications. An increase in the capital labor ration increases the performance of the Greek NFT.

Table 7. Regression Results

\begin{tabular}{|c|c|c|c|c|}
\hline & $\begin{array}{c}\mathrm{q}_{\mathrm{FIFA}} \\
(1)\end{array}$ & $\begin{array}{c}\mathrm{q}_{\text {Elo }} \\
(2)\end{array}$ & $\begin{array}{c}\mathrm{q}_{\mathrm{FIFA}} \\
(3)\end{array}$ & $\begin{array}{c}\mathrm{q}_{\text {Elo }} \\
(4)\end{array}$ \\
\hline $\mathrm{c}$ & 0.16 & -1.72 & $-3.53^{*}$ & $-6.60^{* *}$ \\
& $(0.14)$ & $(-0.79)$ & $(-2.24)$ & $(2.17)$ \\
\hline $\mathrm{k}$ & $0.82^{*}$ & $1.13^{* * *}$ & $1.51^{*}$ & $1.89^{* * *}$ \\
& $(3.50)$ & $(2.51)$ & $(4.52)$ & $(2.95)$ \\
\hline \multirow{2}{*}{$\mathrm{g}_{\text {official }}$} & & & $0.19^{* *}$ & $0.66^{*}$ \\
& & & $(1.98)$ & $(3.55)$ \\
\hline \multirow{2}{*}{$\mathrm{D}_{1}$} & & & $-0.35^{*}$ & $-0.49^{* *}$ \\
& & & $(-2.72)$ & $(-1.96)$ \\
\hline \multirow{2}{*}{$\mathrm{DC}_{1}$} & & & $0.49^{*}$ & $0.90^{*}$ \\
& & & $(3.71)$ & $(3.50)$ \\
\hline $\mathrm{R}^{2}$-adj & 0.1994 & 0.0626 & 0.4601 & 0.4580 \\
\hline $\mathrm{D}-\mathrm{W}$ & 1.83 & 1.82 & 1.70 & 1.83 \\
\hline Obs & 41 & 41 & 41 & 41 \\
\hline
\end{tabular}

* Significant at $1 \%$. **Significant at $5 \%$. t-statistics in brackets. $\mathrm{D}_{1}$ : Dummy for a game played in a European or World Cup Final. $\mathrm{DC}_{1}$ : Dummy for the Greek coach Panagoulias. 
A number of other variables were included but none was statistically significant and therefore they are not reported in Table 7. However, in the remaining of this section I discuss some of these variables which include the role of a foreign or Greek coach, the Bosman impact, the impact of experience accumulated over the years, the years of amateur and professional organization of the Greek Football League and the Olympic effect.

\section{The Role of the Coach}

Good players, good coaches and good national football associations make up a good national football team. Does performance depend on the quality of these three factors? The choice of players is restricted by their nationality as these are defined by FIFA. Players cannot move between national football teams. However, coaches do. This is the reason which explains why many national football teams have hired a foreign coach. A dummy variable for a foreign coach (not reported in Table 7) was not statistically significant for any measure of performance. However, when dummy variables are used for individual coaches, then a Greek coach, Alketas Panagoulias, has had a positive effect on performance. The other two more successful coaches were foreigners but their impact was not statistically significant. The surprising result is that of Otto Rechagel who won the European Trophy with the Greek NFT in 2004. His impact is not statistical significant. The reason is that winning the final game of a European Cup does not give more points than winning any other match of the European final. The result of the foreign coach impact contrasts with the result found by Allan and Moffat (2014). They find a negative impact of a foreign coach. I find no impact but the fact that a Greek coach has had a positive impact might be in agreement with their recommendations that domestic coaches should be hired. I would add though that they should be good because in the history of the Greek football, as it is true in many other aspects of Greek life, nepotism prevents the hiring of the best available. And in such cases hiring a foreign coach might be a good solution.

\section{The "Bosman" Impact}

The Greek national league is a strong one and thus players playing for the best teams in Greece do not lack the experience of other players playing in stronger national leagues. Most of the Greek players playing for a Greek team have experience with the Champions League and other European competitions. Besides before Bosman was very difficult for Greek players to play abroad. A dummy variable to account for the "Bosman Effect" was not statistically significant.

\section{The Impact of Experience and Official Games}

The accumulated number of games played over the years were used as an explanatory variable to account for the experiences acquired by playing more and more games. The variable was found not statistically significant. However, the number of official games played in one year plays a role and has a positive 
impact. This variable may also be interpreted as shown the differences of Greek NFT over the years because more official games can be played per year only if the team qualifies for next rounds of play. However, there is a negative impact as well because as the NFT advances in the next round it plays with stronger and stronger teams. This impact is taken into consideration by a dummy variable which takes the value of zero for final round games such as the World and European Cup. As shown in Table 7, this impact has the expected negative sign.

\section{The Years of the Greek Professional Football League}

In 1979 the Greek national football league became professional. This was expected to improve the quality of football players and make the game more competitive. Players were now working full time in the individual Greek football clubs. This is expected to have a positive impact on the strength of the Greek NFT. A dummy variable with zero values up to 1978 and one thereafter was included in the regression but it was not statistically significant

\section{The Olympic Games Effect}

An important mega event took place during the period under examination and it has been mentioned in the introduction of the papers. In 1997 the International Olympic Committee chose Athens to organize the 2004 Olympic Games. The football tournament of the Olympic Games took place in different cities in brand new or fully renovated football venues. This is expected to have a positive impact on the development of Greek football. A dummy variable with zero values up to 2003 and one thereafter had the expected positive sign but it was not statistically significant.

\section{Conclusions}

This paper develops a production function model to account for the Greek NFT performance in the last 40 years. It was found that the capital-labor ratio has a positive impact on the performance of the national team for both the FIFA and the Elo performance measurements. In addition to capital, an extended model tests a number of hypotheses that relate to determinants of performance. The most important of these are the experience acquired by playing more official games, the strength of opponents as these are measured by the qualification to World and European Finals, the role of the coach, and other variables which were found as statistically non significant.

\section{References}

Allan G. J. \& J. Moffat (2014). Muscle drain versus brain gain in association football: technology transfer through player emigration and manager immigration. Applied Economics Letters, 21 (7), 490-493. 
Hoffman, R., Lee, C. G., \& Ramasamy, B. (2002). The socioeconomic determinants of international soccer performance. Journal of Applied Economics, 5(2), 253-272.

Macmillan, P. \& Smith, I. (2007). Explaining international soccer rankings. Journal of Sports Economics, 8 (2), 202-213. 
